\title{
The Pipe Bomb: A Modern Terrorist Weapon
}

\author{
AJ Gibbons, JN Farrier, SJ Key
}

\begin{abstract}
The use of pipe bombs by terrorist organisations around the world has risen dramatically. The pipe bomb is simple and easy to make and details of bomb construction are freely available from the Internet. Components can be found in most hardware stores and thus give little forensic information.

Despite the increasing use of pipe bombs, clinicians may be unfamiliar with the type of injuries they cause. This paper describes two incidents of pipe bomb explosions and illustrates the type of injuries sustained by both terrorists and victims.
\end{abstract}

\section{Introduction}

Pipe bombs are anti-personnel fragmentation devices that wound, maim and kill. They are simple and cheap to make from components available at any hardware shop. With information on bomb construction easily found on the Internet and in many bookshops, this type of weapon has become one of the main tools of terrorists and criminals around the world. A review of Internet news sites reveals almost daily incidents of pipe bomb use in the USA, Israel, Northern Ireland and South Africa.
The bomb is simply a pipe with threaded ends into which two caps are screwed (Figure 1). A hole is drilled into one cap and a fuse or detonator placed in the defect. Low order explosive is then poured into the pipe and packed tightly with a wad of tissue paper. This prevents the explosive being caught in the thread of the pipe exposing it to friction and accidental detonation. Pipe bombs are potentially unstable and the use of home-made detonators increases the chances of accidental detonation.

The main action of the pipe bomb is to throw out fragments causing multiple shrapnel wounds. Victims of such devices may also suffer blast and thermal injuries.

The following two incidents, occurring in the same city within a short time of each other, illustrate the effectiveness of the pipe bomb and the type of injuries it can cause.

\section{The Cape Town Bombing}

At 19:30 on the evening of Tuesday 25th August 1999 a bomb exploded in the Planet Hollywood restaurant situated in the waterfront tourist area of Cape Town. The bomb killed two people and seriously injured 27. Within minutes paramedics, along with trauma consultants, were on the scene. Casualties were triaged and sent to six different hospitals. By 20:10 all
Wg Cdr A J Gibbons MA(Cantab)

FDS RCS FRCS RAF

Registrar in

Maxillofacial Surgery

e-mail:

andrew_gibbons@hotmail.com

Mr J N Farrier

FDS RCS FRCS RAF

Registrar in

Maxillofacial Surgery

Mr S J Key

FDS RCS FRCS

Staff Grade in

Maxillofacial Surgery

Maxillofacial Unit, Morriston Hospital, Swansea, SA6 6NL.

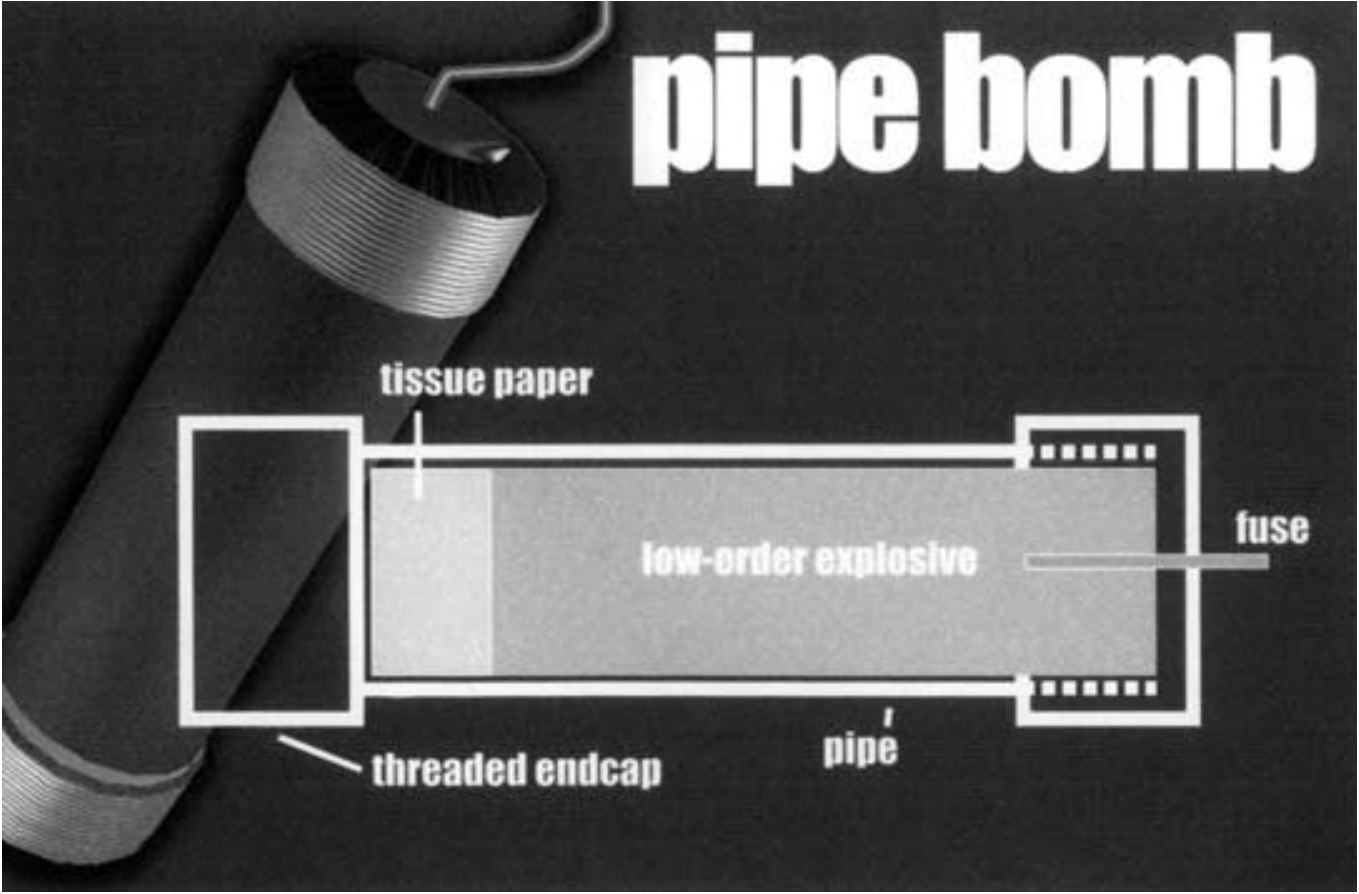

Fig 1. Design of a 'Pipe Bomb'. 


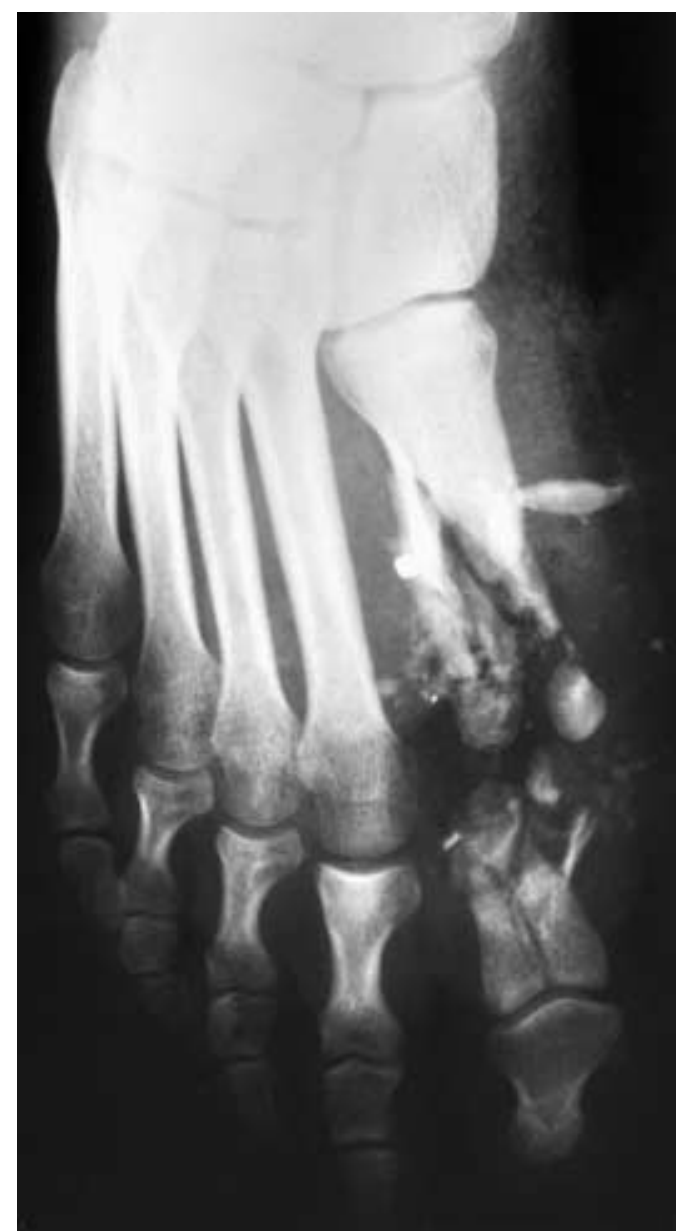

Fig 2. Shattered first metatarsal fragmentation injury.

casualties had been evacuated from the site. Four of these casualties arrived at Groote Schuur Hospital within one hour.

Patient 1 was a 38 year-old Englishman on holiday in Cape Town. He sustained a laceration of his nose, burns to his face, tympanic membrane perforations, shrapnel wounds to his lower limbs and partial amputation of his great toe with a shattered first metatarsal (Figure 2). $\mathrm{He}$ also sustained a fractured ankle. The toe was surgically amputated and the fracture plated.

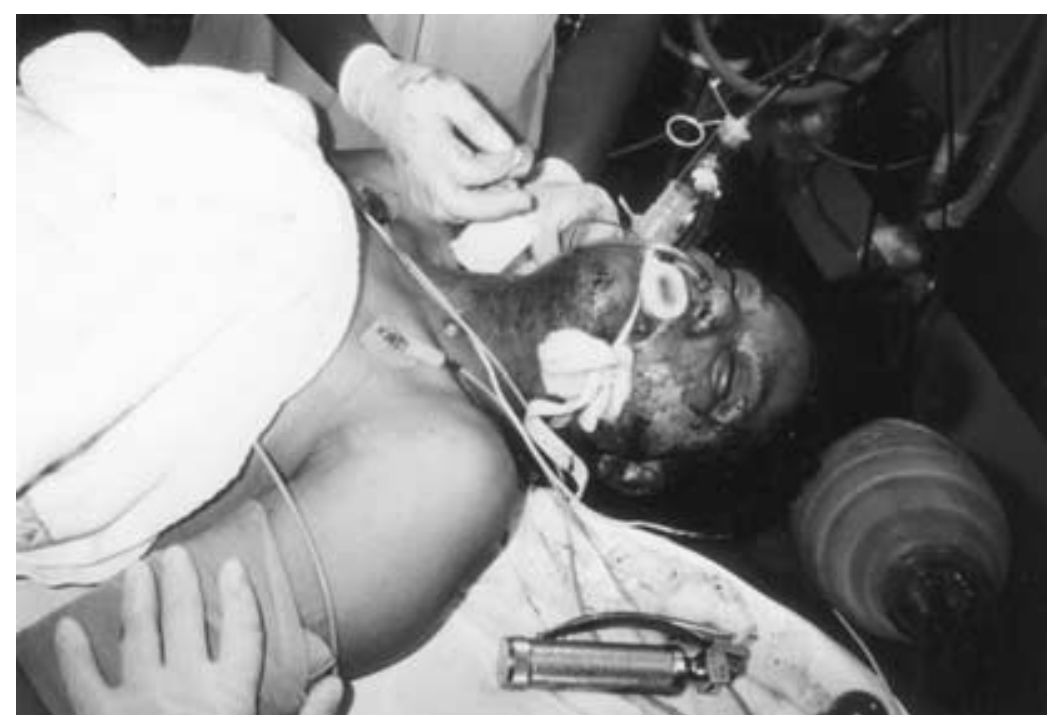

Fig 3.Peri-oral burns indicating potential airway problems.
Patient 2 was a 40 year-old Cape Town woman with full and partial thickness burns to her face, head and neck (Figure 3). She also had shrapnel in both feet. In view of the peri-oral burns and her hoarse voice, she was intubated and admitted to the Respiratory Intensive Care Unit. Her blood gases were normal on admission and her lung fields were clear. However, a subsequent fibre-optic laryngoscopy showed marked oedema of the vocal cords. She made a slow but uneventful recovery.

Patient 3 was a 25 year-old English woman, on holiday in Cape Town, who had shrapnel in both lower legs and a large fragment in her right heel. This had caused a laceration to her Achilles tendon. She also had ruptured tympanic membranes. She was the least injured of the four patients, but the most vocal and required a great deal of reassurance. Her Achilles tendon was repaired the next day under general anaesthetic.

Patient 4 was a 55 year-old Afrikaner woman whose husband died in the explosion. She had shrapnel injuries to her face and legs. The wounds were dressed and physically she made a good recovery.

\section{Unstable Detonation of a Pipe Bomb}

The previous week at Groote Schuur Hospital another patient was admitted to the trauma ward having sustained a pipe bomb injury. He was a Cape Town man aged 39 who had been a passenger in the back of an open-backed pick-up truck when a pipe bomb exploded in the driver's compartment as the vehicle went over a speed restriction bump. The driver was killed instantly, along with the front seat passenger holding the pipe bomb. The passenger's head was found by police a short distance from the pick-up truck.

On examination in the resuscitation bay the patient had sustained two lacerations of his left parietal region and a compound fracture of his left ulna. In addition, he had bilaterally perforated tympanic membranes. He was haematologically stable with a Glasgow Coma Scale of 15. Radiographs revealed a fragment of pipe bomb casing embedded in his parietal bone beneath the anterior skull laceration (Figure 4).

A CT scan demonstrated a minimally displaced skull fracture with a small amount of haematoma beneath it. The patient underwent a craniotomy on the day of admission in order to remove the foreign body. His fractured ulna was plated at the same operation and the forearm wound closed the following day. His perforated tympanic membranes were treated conservatively. Postoperatively the patient made a good recovery and a further CT scan showed no underlying brain contusion. 


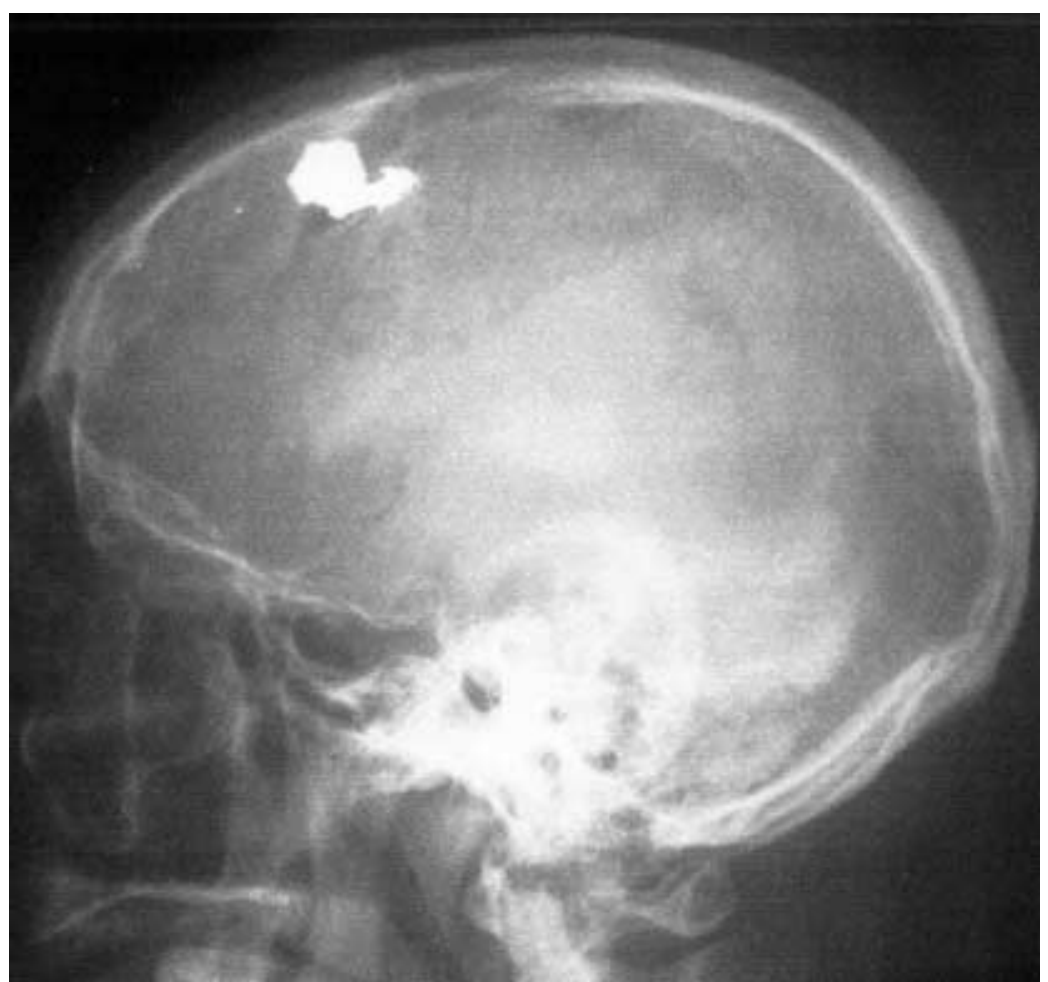

Fig 4. Shrapnel injury to skull. containing organs such as the lungs and intestines (8). The tympanic membranes are particularly susceptible as illustrated by cases 1 and 3. Blast winds are rapidly moving displaced columns of air that follow the blast wave and can produce a range of traumatic soft and hard-tissue damage depending on the distance of the individual from the explosive source $(9,10)$. Secondary blast injuries are due to the products of the explosion. These include the constituents of the bomb and any associated debris that may strike the individual causing fragmentation injuries seen in all the above cases. Tertiary blast injuries occur when the individual becomes the missile and is thrown against a solid object or the ground (5). Amputations, which are also due to the blast wind, are included in this group. Flash burns are usually superficial on exposed skin, but smoke inhalation can cause potentially life-threatening problems in patients who initially have normal airways. Case 3 illustrates the high index of suspicion that is needed in patients with peri-oral burns as they may have inhalation injuries.

Fragmenting weapons produce a variety of missiles of different sizes $(11,12)$. The crude but effective pipe bomb releases low mass, low energy transfer fragments. In a confined civilian setting it can cause multiple casualties making it an ideal terrorist weapon as demonstrated in the Cape Town bombing.

Pipe bombs have become one of the most popular 'tools of terror' in the United States and are particularly favoured by white supremacists and far-right political extremists. Between 1980 and 1990 there were 12,216 bombing incidents in the United States, the majority involving pipebomb devices (2). The Oklahoma bombing in 1995, leading to 167 deaths (13), was caused by a massive pipe bomb whilst the explosion at the Atlanta Games in 1996 involved a much smaller device but still caused one fatality and more than 100 casualties (14). Both incidents gained tremendous media publicity, a key aim of terrorist attacks.

In the 1990 s the incidence of pipe bomb explosions around the world has risen dramatically. In Germany the pipe bomb has become synonymous with neo-Nazi groups (15), whilst in Italy a 'Unibomber' has used several pipe bombs in random attacks. Palestinian terrorists routinely use pipe bombs against Israeli targets with devastating effects (16). In the United Kingdom, the Brick Lane and Soho bombings in London were pipe bomb explosions (17). Between July 1997 and February 2001 in Northern Ireland, both Catholic and Protestant terrorist groups were involved in over 75 media reported incidents of sectarian pipe bomb attacks. injuries result from the direct effects of the pressure wave and cause most injuries to gas 
The more recent throwing of a pipe bomb at police lines outside a Roman Catholic Primary school as children attempted to enter it caused the British Government to be questioned regarding whether the Northern Island cease-fire was still intact (18).

The Cape Town bombing was believed to be the work of a Muslim fundamentalist group in response to the American bombing of Sudan and Afghanistan (19). Over the past 5 years, pipe bombs have been frequently used by vigilante groups and criminals in the Cape metropolitan area.

A common feature of all these attacks is the difficulty in tracing the bombers due to lack of forensic evidence. With conventional bombs much physical evidence can be recovered after a blast, such as the container, trigger or delay mechanisms. Identification and tracing the origin of these components may aid in identifying and convicting the bomber. However, where the components have simply been purchased at a hardware store and the detonator is home made, tracing the manufacturer of the bomb is difficult. In addition, most pipe bombs are small enough to fit in a carrier bag or briefcase and can, therefore, be left inconspicuously.

For terrorists, buying ammunition such as grenades from outside sources represents a risk. In comparison pipe bombs can be made in-house at minimum risk. Unsophisticated home-made detonators and the crude method of manufacture make pipe bombs unstable during construction and transport (20). Terrorists using these devices are occasionally killed or injured, as demonstrated in the second case report.

The exponential increase in pipe bombings around the world in the past decade indicates the ease of manufacture of this type of bomb and the difficulty the police force have in tracing people who use it. The pipe bomb is proving to be a cheap and deadly modern terrorist weapon

\section{Acknowledgements}

We thank Mr A Nichol, Head of the Trauma Unit of Groote Schuur Hospital for his permission to present patients from the Unit.

\section{References}

1. Sampalis J S, Lavoie A, Williams J L, et al. Impact of on-site care, pre-hospital time and level of inhospital care on survival in severely injured patients. F Trauma 1993; 34: 252.

2. Karmy-Jones R, Kissinger D, Golocovsky $\mathrm{M}$, Jordan M, Champion H R. Bomb-related injuries. Mil Med 1994; 159(7): 536-539.

3. Davies E B, Rollins C E, Reiber G D, Anthony R M. Suicide by pipe bomb. Am f Forensic Med Pathol 1999; 20(2): 136-140.

4. American College of Surgeons Committee on Trauma. Advanced Trauma Life Support for Doctors. 6th edn. 1997: 9.

5. De Candole C A. Blast injury. Can Med Assoc f 1967; 96: 207-214.

6. Leibovici D, Gofrit O N, Stein M, Shapira S C, Noga Y, Heruti RJ, Shemer J. Blast injuries: bus versus open-air bombings - a comparative study of injuries in survivors of open-air versus confined space explosions. F Trauma 1996; 41 (6):10301035.

7. Trimble K, Clasper J. Anti-personnel mine injury; Mechanism and medical management. F R Army Med Corps 2001; 147: 73-79.

8. Huang J Z, Yang Z, Wang Z, Leng H. Study on characteristics of blast-fragment combined injury in dogs. F Trauma 1996; 40(3): 63-67.

9. Hull J B, Bowyer G W, Cooper G J, Crane J. Pattern of injury in those dying from traumatic amputation caused by bomb blast. BrF Surg 1994; 81(8): 132-135

10. Hull J B, Cooper G J. Pattern and mechanism of traumatic amputation by explosive blast. F Trauma 1996; 40(3): 198-205.

11. Bowyer G W, Cooper G J, Rice P. Small fragment wounds: Biophysics and pathophysiology. F Trauma 1996; 40(3): 159-169.

12. Spalding T JW, Stewart M P M, Tulloch D N, et al. Penetrating missile injuries in the Gulf War 1991. BrF Surg 1991; 78: 1102

13. Mallonee S, Shariat S, Stennies G, et al. Physical injuries and fatalities resulting from the Oklahoma City bombing. FAMA 1996; 276: 382-387.

14. Reynolds P. World: Americas Fugitive charged with Atlanta bombing. BBC News Online Network 1998; October 14

15. Boyes R. Berlin Sounds alarm as neo-Nazis hoard arms. The Times 2000; June 22.

16. Bamber D. IRA 'is teaching Palestinians how to blow up Israeli soldiers' in West Bank. The Daily Telegraph 2002; April 28.

17. Hopkins N, Hall S. Festering hate that turned quiet son into a murderer. The Guardian 2000; July 1 .

18. Sharrock D. Blair challenged over ceasefire. The Daily Telegraph 2001; September 6.

19. Russell A. City is a stronghold of Muslim militants. The Daily Telegraph 1998; August 27.

20. Sharrock D. Loyalist is killed while working on pipe bomb. The Daily Telegraph 2002; January 5. 